\title{
Medical Image of the Week: Medical Administrative Growth
}

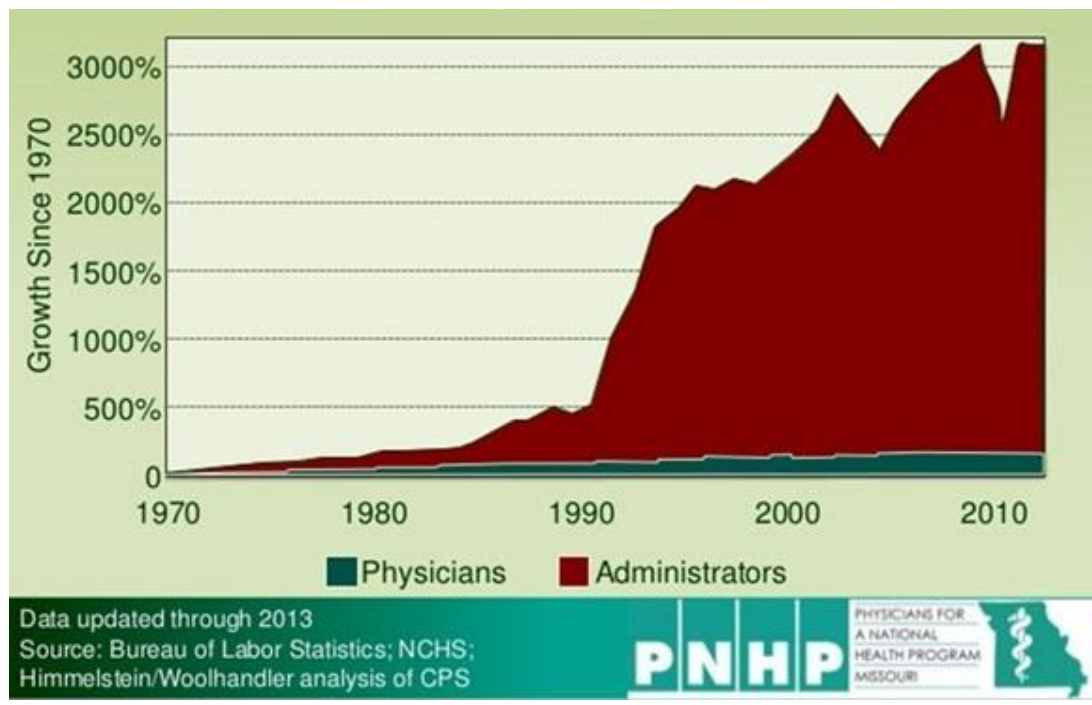

Figure 1. Growth of administrators compared to physicians 1970-2010 (used with permission of David Himmelstein).

It is generally agreed that healthcare costs are too high in the US. Although there has been considerable finger pointing, there is little doubt that administrative costs are far outpacing other healthcare costs. In ground-breaking work published in 1991, Woolhandler and Himmelstein (1) found that US administrative health care costs increased $37 \%$ between 1983 and 1987 . They estimated these costs accounted for nearly a quarter of all health care expenditures. They followed their 83-87 report by examining data from 1999 (2). US administrative costs had risen to $31 \%$ of US health care expenditures. Himmelstein now estimates that administrative costs may now account for up to $40 \%$ of healthcare costs (Robbins RA, personal communication). The trend is perhaps best illustrated by Figure 1 showing growth of administrators compared to physicians from 1970-2010 (3).

Richard A. Robbins $\mathrm{MD}^{1}$ and Bhupinder Natt MD²

${ }^{1}$ Phoenix Pulmonary and Critical Care Research and Education Foundation, Gilbert, AZ USA

${ }^{2}$ University of Arizona College of Medicine, Tucson, AZ USA

\section{References}

1. Woolhandler S, Himmelstein DU. The deteriorating administrative efficiency of the US health care system. N Engl J Med. 1991;324(18):1253-8. [CrossRef] [PubMed]

2. Woolhandler $S$, Campbell T, Himmelstein DU. Costs of health care administration in the United States and Canada. N Engl J Med. 2003;349(8):768-

75. [CrossRef] [PubMed]

3. Bureau of Labor Statistics. NCHS. Himmelstein and Woolhandler analysis of current population survey. Available at: http://www.pnhp.org/ (accessed 7/9/18). 